\title{
Clear cell carcinoma of the ovary in a 24-year-old female associated with endometriosis
}

\begin{abstract}
Clear cell carcinoma (CCC) of the ovary comprises about $7.4 \%$ of ovarian carcinomas and $2.4 \%$ of ovarian epithelial neoplasms. The average age at the time of diagnosis ranges from 48 to 58 years. A close association between CCC and endometriosis has been documented in the previous series with documentation of transition from endometriosis to CCC in few series. Fifty percent of cases of CCC are stage I at the time of diagnosis, and $15 \%$ are stage II. Yolk sac tumor (YST) can have a variety of morphologic patterns, some of which can resemble CCC. The distinction between YST and CCC is important for the clinical management of patients. Immunohistochemistry (IHC) may be mandatory for differentiating these tumors in cases with diagnostic difficulty. We report a case of a 24-year-old female diagnosed to have CCC associated with endometriosis. We wish to highlight the role of IHC in such diagnostically difficult cases.
\end{abstract}

Volume 2 Issue I - 2017

\author{
Nalini Gupta,' Arvind Rajwanshi,' Vanita Suri² \\ 'Department of Cytology and Gynaecologic Pathology, \\ Postgraduate Institute of Medical Education and Research, India \\ ${ }^{2}$ Department of Obstetrics and Gynaecology, Postgraduate \\ Institute of Medical Education and Research, India
}

\begin{abstract}
Correspondence: Nalini Gupta, Department of Cytology and Gynecological Pathology, Postgraduate Institute of Medical Education and research, Chandigarh, India, Tel +9|- |72-2755 I |4, Fax+9I-I72-274440I, Email nalini203@gmail.com
\end{abstract}

Received: November 12, 2016 | Published: January 02, 2017

Keywords: clear cell carcinoma, immunohistochemistry, ovary, yolk sac tumor

Abbreviations: CCC, clear cell carcinoma; IHC, immuno histo chemistry; YST, yolk sac tumor; LDH, lactate dehydrogenase; PAS, periodic acid schiif stain; EMA, epithelial membrane antigen; CK, cytokeratin; AFP, alpha fetoprotein

\section{Introduction}

Clear cell carcinoma (CCC) represents $2-10 \%$ of all epithelial ovarian cancers. $24-50 \%$ of the patients are known to have associated pelvic endometriosis. Women typically present between the ages of 40 and 70 with the peak incidence at age 52. CCC is rarely described in young females with youngest reported age being 23 years. ${ }^{1}$ Risk factors for ovarian cancers include family history, age and nulliparity. The condition is classically associated with dysmenorrhoea, deep dyspareunia and infertility. Endometriosis, a common benign gynaecologic condition, has been reported in association with certain epithelial ovarian tumours. According to a previous report, the rank order of the prevalence of endometriosis in each histologic type is clear cell $(39.2 \%)>$ endometrioid $(21.2 \%)>$ serous $(3.3 \%)>$ mucinous type $(3.0 \%){ }^{2}$ Scully and Barlow in 1967 established the close association between CCC, endometrioid carcinoma of the ovary and endometriosis. ${ }^{3}$ We present a case of CCC associated with endometriosis in a 24-year-old young female with immunohistochemistry (IHC).

\section{Case presentation}

A 24-year-old unmarried female was referred to the Department of Obstetrics \& Gynaecology in June 2010 with a history of recurrent endometriosis-associated pelvic pain and excessive dysmenorrhoea for the last 2years. She was diagnosed to have bilateral ovarian cysts measuring $7.4 \times 7 \mathrm{~cm}$ on right side and $2.5 \times 2 \mathrm{~cm}$ on left side in April 2008. The symptoms were relieved with oral analgesics and oral contraceptive pills till 2009. The symptoms recurred in the year 2010 and on per-abdominal examination; a firm mass was palpable in right lower abdomen. Ultrasonography revealed a large complex cystic adnexal mass measuring $18 \times 16 \mathrm{~cm}$ with echogenic nodules and papillary excrescences. There was a small cyst in the left ovary about 1 $\mathrm{cm}$ diameter. $\alpha$-fetoprotein and $\beta$-hCG were normal; however, CA125 and $\mathrm{LDH}$ were raised. The patient underwent exploratory laparotomy with right salpingo-oophorectomy. Intra-operatively, left ovary was seen buried in dense adhesions with gut and sigmoid colon. Ascites was present, was sampled for cytologic examination and was reported as negative for malignant cells.

Grossly, the right ovary was enlarged and was totally replaced by a tumor measuring $15 \times 13 \times 6 \mathrm{~cm}$. The external surface was smooth, lobulated and red-grey in colour. On cut section, the tumor was predominantly cystic $(70 \%)$ and showed focal solid areas (30\%) with many papillations and polypoid projections. No residual normal ovarian tissue was identifiable. Microscopically, the tumour was composed of papillary and tubule-cystic patterns lined by predominantly clear to eosinophilic cells with sharply demarcated cell borders, had pleomorphic vesicular nuclei and conspicuous nucleoli (Figure 1). Occasional Schiller-Duval body like structures are seen along with numerous Periodic-acid Schiff's stain (PAS) - positive diastase resistant extracellular hyaline globules (Figure 2A). In addition, the serosal aspect of the same side fallopian tube had foci of endometriosis. Based on the morphology and age, the possibilities of yolk sac tumour and clear cell carcinoma were considered. IHC panel comprising of cytokeratin 7 (CK7), Epithelial membrane antigen (EMA), CD15 and $\alpha$ FP was performed. The tumour cells were strongly positive for CK7 and EMA and negative for $\alpha$ FP (Figure 2). CD15 was non-contributory. Hence, based on the morphology and IHC findings, a diagnosis of clear cell carcinoma associated with endometriosis was offered. The tumor was stage $1 \mathrm{~A}$ as per FIGO ovarian cancer staging. She was given five cycles of Cisplatin based chemotherapy and she was well after four years and two months of follow-up. 


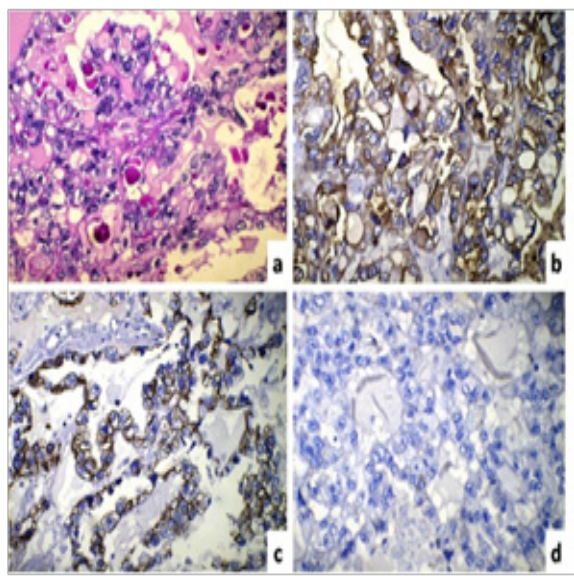

Figure I Clear cell carcinoma ovary.

(A) Gross of the cystic ovarian tumor with smooth external surface and solid areas having polypoid projections

(B) Cystic spaces lined by multilayered clear cell to tall columnar epithelium (H\&ExIOX).

(C) Papillary to tubule-cystic pattern of tumor cells (H\&ExIOX).

(D) Clear to eosinophilic cells with sharply demarcated cell borders and pleomorphic vesicular nuclei with numerous extracellular hyaline globules (H\&Ex40X).

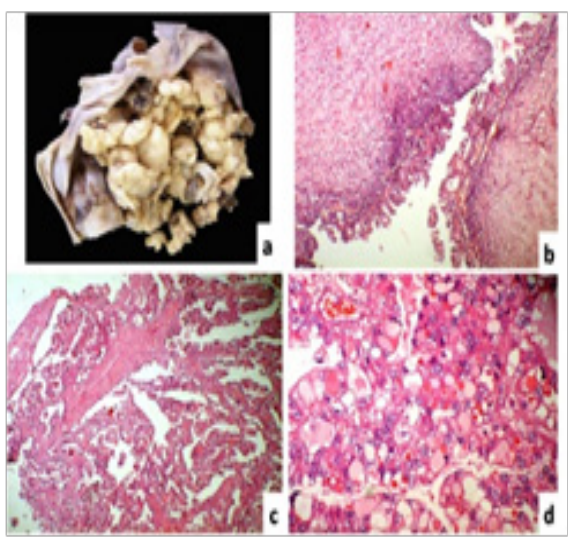

Figure 2 Clear cell carcinoma ovary.

(A) Many PAS positive hyaline globules (PASx40X).

(B) Tumour cells positive for epithelial membrane antigen (Immunostain $x 40 X)$.

(C) Tumor cells positive for cytokeratin7 (Immunostainx40X).

(D) Tumor cells negative for $\alpha$-fetoprotein (Immunostainx40X).

\section{Discussion}

Clear cell carcinoma (CCC) was first described in $1939,{ }^{4}$ and was classified as a subgroup of epithelial ovarian carcinoma. The clinical features include abdominal or pelvic mass, abdominal distension or pain. Women typically present between the ages of 40 and 70 with the peak incidence at age 52 . We presented this case in a young 24-yearold unmarried female. Takano $\mathrm{M}$ et al. ${ }^{1}$ analyzed 254 cases of CCC with a mean age of 52.3years (range 23-73 years). Ryu SY et al., 5 analyzed 150 cases of CCC with a median age of 46.8 years. Malignant transformation of endometriosis in gonadal and extra gonadal sites has been well documented since Sampson ${ }^{4}$ reported the first case in 1925 . An interesting point in the present case is that clear cell carcinoma was detected within two years of diagnosis of endometriosis. On microscopic examination, yolk sac tumor was considered a strong possibility based on the presence of PAS positive hyaline globules as well as Schiller-Duval like bodies. Cytohistomorphological differences between CCC and YST have been enlisted in Table $1 .{ }^{6}$ This case also highlights importance of IHC in such difficult cases. Table 2 shows immunohistochemical markers helpful to differentiate between CCC of the ovary and YST. ${ }^{7-10}$ Clear cell carcinoma of the ovary are known to be positive for CK7, EMA and Leu M1/ CD15 as compared to yolk sac tumor. CK and EMA were positive in the present case; however CD15 was non-contributory due to technical error. Napsin A has been identified as a newer marker, which shows positivity in approximately $85 \%$ CCC of the ovary. ${ }^{9}$ SALL4 is another sensitive immunohistochemical marker, which is useful to differentiate YST from CCC. Glypican-3 is an oncofetal protein, which is expressed in germ cell tumors, particularly YST. Based on age and morphology, a differential diagnosis of YST and CCC of the ovary was considered in the present case and IHC was useful to clinch the diagnosis as CCC of the ovary. Dysgerminoma, Krukenberg tumor, metastatic renal cell carcinoma, and struma ovarii are less common entities that may cause diagnostic difficulty at times.

Table I Pathologic features to differentiate clear cell carcinoma of the ovary from yolk sac tumor

\begin{tabular}{lll}
\hline Pathologic features & $\begin{array}{l}\text { Clear cell } \\
\text { carcinoma }\end{array}$ & Yolk sac tumor \\
\hline Tumor pattern & $\begin{array}{l}\text { Tubulo-papillary, } \\
\text { solid }\end{array}$ & $\begin{array}{l}\text { Various patterns } \\
\text { described }\end{array}$ \\
$\begin{array}{l}\text { Fibro-vascular septae } \\
\text { Cellicate, Hyalinized }\end{array}$ & $\begin{array}{l}-+ \\
\text { Schiller-duval like }\end{array}$ & + \\
bodies & ++ & ++ \\
$\begin{array}{l}\text { Nuclear pleomorphism } \\
\text { Cytoplasmic outlines }\end{array}$ & + Better preserved & Faint and delicate \\
$\begin{array}{l}\text { Nuclear membrane } \\
\text { Nucleoli }\end{array}$ & Smooth thickened & Not thickened \\
$\begin{array}{l}\text { Multi nucleation } \\
\begin{array}{l}\text { Cytoplasmic } \\
\text { vacuolation }\end{array}\end{array}$ & + & +++ \\
$\begin{array}{l}\text { Hob-nailing of tumor } \\
\text { cells }\end{array}$ & + & ++ \\
$\begin{array}{l}\text { PAS positive hyaline } \\
\text { globules }\end{array}$ & + & ++ \\
\hline
\end{tabular}

Table 2 Immunohistochemical markers to differentiate clear cell carcinoma of the ovary from yolk sac tumor

\begin{tabular}{lll}
\hline IHC markers & Clear cell carcinoma & Yolk sac tumor \\
\hline CK7 & + & - \\
EMA & + & - \\
CDI5/Leu MI & + & - \\
Napsin A & + & - \\
AFP & - & $+/-$ \\
Glypican3 & - & ++ \\
SALL4 & - & ++ \\
\hline
\end{tabular}




\section{Conclusion}

In conclusion, the association of endometriosis and clear cell carcinoma of the ovary should be kept in mind, mainly in patients with a persistent ovarian cyst irrespective of the age.

\section{Acknowledgements}

None.

\section{Conflict of interest}

The author declares no conflict of interest.

\section{References}

1. Takano M, Kikuchi Y, Yaegashi N, et al. Clear cell carcinoma of the ovary: a retrospective multicentre experience of 254 patients with complete surgical staging. Br J Cancer. 2006;94(10):1369-1374.

2. Hiroyuki Yoshikawa, Haruko Jimbo, Satoshi Okada, et al. Prevalence of endometriosis in ovarian cancer. Gynecol Obstet Invest. 2000;50(Suppl 1):11-17.

3. Sampson JA. Endometrial carcinoma of ovary, arising endometrial tissue in that organ. Arch Surg. 1925;10(1):1-72.
4. Scully RE. Recent progress in ovarian cancer. Hum Pathol. 1970;1(1):73-98.

5. Ryu SY, Park SI, Nam BH, et al. Prognostic significance of histological grade in clear-cell carcinoma of the ovary: a retrospective study of Korean Gynecologic Oncology Group. Ann Oncol. 2009;20(6):1032-1036.

6. Kuwashima Y, Uehara T, Kurosumi M, et al. Cytological distinction between clear cell carcinoma and yolk sac tumor of the ovary. Eur $J$ Gynaecol Oncol. 1996;17(5):345-350.

7. Ramalingam P, Malpica A, Silva EG, et al. The use of cytokeratin 7 and EMA in differentiating ovarian yolk sac tumors from endometrioid and clear cell carcinomas. Am J Surg Pathol. 2004;28(11):1499-505.

8. Cao D, Guo S, Allan RW, Molberg KH, et al. SALL4 is a novel sensitive and specific marker of ovarian primitive germ cell tumors and is particularly useful in distinguishing yolk sac tumor from clear cell carcinoma. Am J Surg Pathol. 2009;33(6):894-904.

9. Yamashita Y, Nagasaka T, Naiki-Ito A, et al. Napsin A is a specific marker for ovarian clear cell adenocarcinoma. Mod Pathol. 2015;28(1):111-117.

10. Esheba GE, Pate LL, Longacre TA. Oncofetal protein glypican-3 distinguishes yolk sac tumor from clear cell carcinoma of the ovary. Am J Surg Pathol. 2008;32(4):600-607. 